Original article

\title{
BARRIERS TO GREEN SUPPLY CHAIN MANAGEMENT (GSCM) ADOPTION ON CONSTRUCTION PROJECTS
}

\author{
Benedict Amade ${ }^{1}$, Abiola Adeniyi Adeyomo ${ }^{2}$, Achimba Chibueze Ogbonna ${ }^{3}$, \\ Ogaga Linus Okore ${ }^{4}$, Ihuoma Deborah Okwara ${ }^{5}$
}

\author{
${ }^{1,2,5}$ Federal University of \\ Technology, Department of \\ Project Management \\ Technology, Owerri, Nigeria \\ ${ }^{3}$ Babcock University, \\ University School of \\ Computing and Engineering \\ Science, Ileshan, Remo, \\ Nigeria \\ ${ }^{4}$ Ahmadu Bello University, \\ Department of Building, \\ Zaria, Nigeria
}

Received:15 October 2020 Revised: 30 October 2020 Accepted: 20 November 2020

\section{INTRODUCTION}

According to Peprah et al. (2016), the drive towards green supply chain management (GSCM) for reasonable development in the construction industry is quickly expanding because of ecological debasement brought about by man's exercises in business organizations particularly in the construction
Abstract: The purpose of this paper is to explore barriers to green supply chain management (GSCM) implementation in the Nigerian construction industry with a view to providing a sustainable environmental friendliness and green construction practice. The research approach deployed for this study includes targeting purposively selected construction firms that are involved in GSCM in construction related projects in Imo State, Nigeria. A questionnaire survey was deployed amongst a sample of construction firms. Barriers to GSCM implementation were identified via an extensive literature review. Specifically, data for the study was acquired via questionnaires from relevant industry practitioners. The study was limited to construction firms that are involved in GSCM related activities within Imo State which is located within the high construction /'Niger Delta' hub of Nigeria. With the limited nature of the study in terms of geographic coverage, the results from this study can be extrapolated to cover other parts of the country. The findings revealed that barriers to GSCM implementation were mostly lack of knowledge and experience which headed the list of barriers as stated by the respondents. This is followed in that order by lack of top management support, cost of implementing GSCM, lack of government regulations and support systems amongst others were ascertained to be obstacles to GSCM implementation in Imo State. The study concludes by recommending that a more detailed analysis be carried out with a view to building the capacity of practitioners in GSCM pursuant to better construction project performance.

Keywords: Barriers, construction industry, construction projects, green supply chain management, Imo State. business which has become a central question of worry to academics, experts, governments, social orders and clients. Ecological debasement has caused environmental change, a worldwide temperature alteration, exhaustion of the ozone layer and the preferences with its attendant results on both man and the biological system (Khan, 2018). This circumstance, when left unchecked,

Corresponding author. Email: benedictamade@ futo.edu.ng

ISSN 2560-4961 (online)

Copyright (C) 2020, The Authors. Published by IPMA Serbia.

This is an open access article under theCC BY-NC 4.0 license (https://creativecommons.org/licenses/by$\mathrm{nc} / 4.0 /$ ) 
could compromise the eventual fate of individuals just as their abilities to address these issues. The requirement for GSCM is persuaded by two reasons as per Alhamali (2019) which are social strain to secure the earth, improve organizations integrity as well as competiveness with government, meet market and end-clients request. GSCM has without a doubt has become a genuine practice for reasonable construction which ensures the streamlining of assets and is observed as answer for illuminating natural and asset utilization challenges within the entire supply chain management (SCM) without compromising ecological integrity (Alhamali, 2019).

GSCM fundamentally incorporates ecological reasoning activity and advancement into SCM with each green based action (Khan, 2018; Peprah et al., 2016). This green based exercises which are otherwise called sustainable construction measures incorporates; phases of pre-plan, procurement, construction, activity, upkeep, renovation, recreation, destruction (end-life) and reusing just as other related exercises all through the whole supply chain (Persson, et al., 2008). In spite of the above named sustainability advantages of GSCM challenges, this paper explores the hindrances to GSCM execution in the Nigerian construction industry, proposes techniques for the usage with the end goal of empowering investment by construction industry practitioners.

The low degree of awareness (Ojo, et al., 2014) of GSCM studies and its usage can be said to correspond, to a limited extent, with the scarcity of studies. As stated by Balasubramanian (2012), the negative effect of construction, particularly, ecological degradation resulted into the commitment of 30-40 percent of the world's all out carbon emission (including the Nigerian construction industry) and this has prompted a worldwide temperature alteration, environmental change, ozone layer erosion and green house impact with its ensuing consequences. Besides, the huge use and proceeding with exhaustion of natural assets, contamination of nature and high energy utilization among others offered the opportunity to integrate ecological and green-consistent practices in a bid to ensure the earth and environment is safe for sustainable construction. The previous realities regardless, numerous challenges actually continue militating against the effective implementation of GSCM in the construction sector.

It is fascinating to note that a great deal of studies on barriers to GSCM execution in construction projects have been carried out previously. Some of the investigations were done in construction related industry and other non construction related enterprises. The under listed researchers directed their investigations in a construction related industry, Balasubramanian (2012) (Dubai, United Arab Emirate); Ojo et al. (2014) (Lagos, Nigeria); Kulkarni et al. (2017) (India); Davies and Davies (2017) (Nigeria); Enshassi and Mayer (2005) (Palestine); while in the non construction related businesses, Dashore and Sohani (2013) (India); Mathiyazhagan et al. (2013), (India, automobile fabricating); Govindan et al. (2014) (India, fabricating businesses); Luthra et al. (2011) (India, car industry) Niemann et al. (2016) (Mozambican assembling industry) among others. A glance at the literary works will uncover that nothing unless there are other referenced investigations on barriers to GSCM has been carried out in the area of study (Imo State, Nigeria), hence, this investigation expects to fill in this gap (area based exploration study) since there no known researches on hindrances to GSCM to the best of this researchers knowledge.

\section{REVIEW OF RELATED LITERATURES}

The development business' high asset/vitality utilization, ecological contamination, wastage, etcetera, requires positive GSCM practices as an alleviating methodology (Balasubramanian, 2012) and to incorporate condition based speculation into SCM for sustainable construction and the entrenchment of green building practices (Peprah et al., 2016). In spite of the developing concern, in any case, numerous construction organizations can't effectively execute GSCM practices because of various requirements thus the need for conscious integration of SCM into GSCM (Wyawahare, \& Udawatta, 2017). 
According to Niemann et al. (2016), GSCM is the process of integrating environmental issues into supply chain inputs and transforming these inputs into outputs that can be reclaimed after its useful lifecycle. While Kulkarni et al. (2017) and Srivastava (2007) view it as an integration of environmental issues into SCM that results into product design, material purchasing, products manufacturing and processes, product delivery and management of products after useful-life. Based on the above definitions, GSCM is actually considered in construction to cover some basic aspects related to construction firms and to inculcate environmental responsibility, environmental performance and delivery of green products (Alhamali, 2019).

GSCM aims at reducing environmental degradation caused by construction related emissions of carbon, hence the rational for integrating environmental thinking, initiative and innovation into SCM (Ahmed et al., 2018). GSCM encompasses direct involvement of organizations with its suppliers and end-users in planning jointly for remedies to reduce environmental hazards from production and construction processes as well as products for environmental management and exchange of vital information and technology with willingness to study and learn about one another's operational plans and set goals for environmental sustainability (Kumar, \& Shekhar, 2013). It is also imperative to show desirable consideration for customer's demand based on green activities in construction theory and SCM technology (Benny, \& Joy, 2018).

Although research has confirmed the benefits of GSCM implementation as a means to curb environmental challenges, some construction firms seem not to be fully convinced about its workability, while others are inhibited from doing so by numerous barriers (Alhamali, 2019).

\subsection{GSCM in construction: sustainable construction and sustainable building}

Sustainable construction according to Persson et al. (2008) is concerned with the whole process of construction in terms of the final product and during the product life time which includes the "stages of pre-design, procurement, construction, operation, maintenance, refurbishment, reconstruction, demolition and recycling". Whereas sustainable building involves the final product (buildings as well as infrastructures) which is a subset of sustainable construction.

Sustainable construction requires the designers and contractors to adopt building practices that will not create negative impact in the long term on the environment, this in a way centers on principle of people, environment and profit (Davies, \& Davies, 2017). In the same vein, Zuofa and Ochieng (2017) noted some benefits cited in the report of the World Resource Institute in 2006 which stressed that sustainable construction practices can generate increased market shares, profitability and other important benefits such as recognition of regulatory bodies, improved stakeholder cum shareholder relation and employee satisfaction at the end of the day.

Dassah and Nimlyat (2010) similarly lend credence to the fact that sustainable buildings or (green construction) encourage buildings that are durable and environmentally friendly as well as "incorporate energy-efficient principles and the physical and psychological sense of well-being experienced by the building occupants".

GSCM practices have been investigated as a means in the construction industry to achieve environmental sustainability as regards sustainable construction and sustainable buildings (process and final products) in the built environment to reduce waste and environmental pollution (Dashore \& Sohani, 2013). Studies on GSCM in the developed countries of the world have been quite successful, whereas the opposite is the case in developing countries of the world, especially Nigeria where Ojo et al. (2014) identified low level of awareness as one of the hiccups to GSCM implementation.

\subsection{Construction industry in Nigeria and its level of application of GSCM}

Construction activities like building and other 'hard' infrastructure projects involve many organizations in its supply chain. Moreover, 
the process of construction includes predesign decisions that consider cost and time as well as planning, sourcing and selection of materials, logistics-warehousing and transportation. Others are production management, monitoring and inspection as well as implementation and integrating of SCM practices which requires all important supply chain stakeholders' engagement (Wibowo et al., 2018). This clearly indicates that operationalizing GSCM cannot be feasible without the involvement of all levels of construction- downstream, midstream and upstream.

The Nigerian construction industry is characterized by small and medium sized local contractors and major contractors as well. The former is mainly involved in private projects and commonly known as informal or unorganized sector responsible for simple residential building projects constructed by private clients through the effort of hired artisans and labourers. In some cases, construction activities maybe supervised by the owner directly with or without government's direct influence on the sector, whereas the 'major contractors' who belong to the formal sector comprises of established contractors who are formally registered to carryout construction business through highly skilled workers, expatriates and local labourers as well as operate under a given set of rules and regulations of the country (Ahiakwo, 2014).

The Nigerian construction industry faces enormous challenges in managing its supply chain which is necessary for a successful project delivery (Abah, \& Adamu, 2017). Ojo et al. (2014) empirically studied GSCM and its successful implementation in Lagos State being Nigeria's hub and home to the megacity of Nigeria. The study fully represents the Nigerian construction scenario and like it was rightly observed, the study is relatively new especially in the construction industry and given that the level of awareness is low, there is need to sensitize all stakeholders in the construction industry.

\subsection{Barriers militating against successful implementation of GSCM}

Barriers and inhibitors of GSCM in the construction industry belong to the class 44 internal and external barriers. Internal barriers include: financial constraints, changing mindset and cultural belief, cost of implementing green supply chain of an organization, lack of commitment from leadership and top management in steering the organization to a new direction, lack of resources (ranging from technical know-how, technology, green material and process), lack of knowledge and experience, lack of managing standard of environmental control policies among others (Balasubramanian, 2012; Dashore, \& Sohani, 2013; Ojo et al., 2014; Wyawahare, \& Udawatta, 2017).

On the other hand, external barriers includes: lack of green suppliers and products, lack of government regulations and support system, lack of public awareness and demand, project sponsors reluctantly avoiding adoption of innovative technologies, competitive pressure and market uncertainty, lack of coordination and cooperation between various supply chain stakeholders, lack of environmental regulations and monitoring plans amongst others (Balasubramanian, 2012; Elbarkouky, \& Abdelazeem, 2013; Enshassi, \& Mayer, 2005; Niemann et al., 2016). Some of the selected barriers to GSCM relevant to the construction industry are illustrated below:

Lack of government regulations and support system: Government may act as both driver and barrier as government is responsible for setting environmental regulations for construction industry and if regulations are not present, organizations will not be obliged to engage in green practices, just as lack of government support systems remains the most dominant barrier to GSCM practices in construction firms (Balasubramanian, 2012; Elbarkouky, \& Abdelazeem, 2013; Niemann et al., 2016)

Lack of knowledge and experience: The lack of knowledge of GSCM is seen as one of the greatest barriers to successful GSCM implementation as it is difficult to engage in what one is ignorant about, hence too complex to fathom (Balasubramanian, 2012; Niemann et al., 2016). Ojo et al. (2014) also identified lack of knowledge and experience as the major barrier of GSCM implementation in the Nigerian construction industry and stressed on the need for sensitization and campaign to all and sundry in the construction industry. 
The cost of implementing green supply chain: The high cost of initiation of GSCM and its processes such as product design, material sourcing and selection, production processes, delivery of the final product to endusers and recycling after useful life and management (Srivastava, 2007; Walker et al., 2008) act as a barrier and discourage organizations from implementation of green supply chain. In the same vein, Niemann et al. (2016) categorizes GSCM practices such as "direct and transaction cost" while noting the likelihood of both costs constituting major barriers to successful implementation of GSCM just as Abbasi and Nilsson (2012) note the difficulty between reducing environmental impact of business activities and increasing financial cost.

Lack of top management support in steering the organization in a new direction: Balasubramanian (2012) and Niemann et al. (2016) identified lack of top management commitment in engaging GSCM as a barrier due to its high driving power and ability to enforce compliance. Coupled with its responsibility to promote, empower employees, increase employees' involvement and increase commitment which can be achieved by motivation of employees and training and re-training of employees and effective communication within all levels of the organization.

Technology (lack of resources): The effect of technical barriers are lack of eco-building materials, lack of technical know-how, persistent skills and labour shortages among others are considered as technical barriers that greatly impede the successful implementation of sustainable construction principles (Balasubramanian, 2012; Davies \& Davies, 2017; Enshassi \& Mayer, 2005).

Mindset and cultural belief: Mindset and cultural belief at all levels are other challenges militating against implementation of GSCM in the construction industry coupled with a great challenge in incorporating sustainable construction, green buildings and environmental management principles into the daily decision making processes carried out in supply chains. In order to overcome the above named constraints, the mindset of supply chain managers and logisticians need to change and GSCM issues taken for granted be reassessed by top management and coworkers alike in the industry (Abbasi, \& Nilsson, 2012). Construction in Nigeria actually favours the use of blocks and reinforced concrete normally termed as wet construction and disregard for other forms of construction practiced in other parts of the world as well as lack of sustainability measures by consultants are considered a major challenge as building projects cannot be constructed with sustainability in view without sponsors or developers full consent for GSCM principles (Davies, \& Davies, 2017; Zulkefli et al., 2019).

Uncertainty: A look at the literature reviewed raises some issues on a number of uncertainties ranging from government actions and decisions, customer behaviour and demands as well as competitive advantage. Organizations consider uncertainty as that situation that may or may not be encountered and so organizations are enjoined to take advantage of it by exploring, promoting and communicating different business issues encountered there by establishing new paths which can fit into environmentally friendly programmes as good policy measures (Abbasi, \& Nilsson, 2012; Balasubramanian, 2012).

\section{RESEARCH METHODOLOGY}

To explore the main barriers to GSCM implementation with respect to construction projects in the study area, an explorative questionnaire survey was conducted among a sample of selected construction firms in various locations within Imo State, Nigeria. The questionnaire was designed and distributed via online and face-to-face modes with a view to facilitating ease of response.

The survey process began on 1 June 2018 and responses were retrieved up to 30 June 2019. Two hundred and fifty two (252) responses were retrieved, while two hundred and twelve (212) responses were found usable. The questionnaire was designed after an extensive literature review on the constraints/barriers GSCM implementation on construction projects in general. The questionnaire was pilot tested with construction industry professionals, thereafter the variables were 
approved and the questions redesigned to convey the right information to the respondents. The questionnaire was addressed to professionals in the industry. A pilot survey consisting of about 25 respondents was earlier conducted with a view to eliminating shortcomings as well as confirming the userfriendliness of the questionnaire before the production of the final copy.

The questionnaire was divided to two parts; the first part was dedicated to information about demographics of both the organization and the respondents. While the second part was related to questions bordering on the barriers to GSCM implementation in general. A Likert five point scale was used in eliciting information from the respondents viz (Strongly agree, Agree, Not sure, Disagree, strongly disagree). The outcome of the statistical inference was based on the respondents' level of agreement with each statement on the scale. The questionnaire responses were given by persons who held strategic positions in the construction firms studied and consisted of project managers, civil engineers, builders, quantity surveyors, estate surveyors, and etcetera. The retrieved questionnaires were sorted in the first instance, while missing data were discarded and treated as invalids. Statistical Package for Social Science (SPSS version 22.0 for Windows) was used in analyzing the contents of the questionnaire survey. While the internal consistency of the survey was assessed using the Cronbach's alpha coefficient to test the reliability of the five-point Likert scale (Saunders et al., 2007).

Mean score was used to analyze the findings among the potential barriers for GSCM implementation. The ranking of the importance of the barriers was achieved based on the mean scores associated with standard deviations (Somekh \& Lewin, 2004).

\section{RESULTS AND ANALYSIS 4.1 Respondents' profiles}

The analysis was based on 212 valid questionnaires ( $74.9 \%$ response rate) retrieved from a total of two hundred and eighty three (283) copies administered. The respondents were distributed as; architects (12.74\%), project managers $(10.85 \%)$, estate surveyors $(15.09 \%)$, quantity surveyors $(20.75 \%)$, civil engineers $(17.45 \%)$, builders $(14.62 \%)$, and others $(8.49 \%)$. About $(31.13 \%)$ of the respondents had experience spanning 11-20 years in the industry, while $(10.85 \%)$ had the least years of professional experience ranging from 1-5 years. The results of the educational qualifications of the respondents showed that (58.02\%) had a first degree and its equivalent, $(40.01 \%)$ had a master's degree, (1.89\%) obtained a Ph.D. From the profile of the respondents, it imperative to state that the professionals are experienced in their various fields of endeavour, hence the data obtained from them are adjudged reliable and it will be suitable for purposes of making informed and reliable decision.

Table 1: Respondent's profile

\begin{tabular}{lcc}
\hline Profile & Frequency & Percentage \% \\
\hline Educational qualification & 123 & \\
B.Sc./HND & 85 & 58.02 \\
M.Sc/M.Eng/MBA & 4 & 40.01 \\
Ph.D & & 1.89 \\
\hline Professionals & 27 & \\
Architects & 44 & 12.74 \\
Quantity Surveyors & 31 & 20.75 \\
Builders & 23 & 14.62 \\
Project Managers & 32 & 10.85 \\
Estate Surveyors & 37 & 15.09 \\
Civil Engineers & 18 & 17.45 \\
Others & & 8.49 \\
\hline Years of Experience & 23 & \\
1-5 years & 54 & 10.85 \\
6-10 years & 66 & 25.47 \\
11- 20 years & 45 & 31.13 \\
21- 30 years & 24 & 21.23 \\
31- 40 years & & 11.32 \\
\hline
\end{tabular}




\subsection{Reliability testing}

The reliability of scaled questions was confirmed using the Cronbach's alpha coefficient. Table 2 below depicts a summary of the reliability test for the barriers to GSCM. The Cronbach's coefficients for the seven (7) barriers are as shown in table 2. From the table, it is clear that the reliability values of the seven barriers to GSCM are above 0.5 and this is an indication that they satisfy the reliability test requirements (Pallant, 2005).

Table 2: Reliability tests

\section{Barriers to GSCM implementation Lack of government regulations and support \\ 1 systems \\ 2 Cost of implementing GSCM \\ 3 Mindset and cultural belief \\ 4 Lack of top management support \\ 5 Uncertainty \\ 6 Lack of knowledge and experience \\ 7 Technology (lack of resources) \\ 4.3 Barriers to GSCM implementation on construction projects}

Seven main barriers to GSCM implementation were identified from the literature consisting of lack of government regulations and support systems, mindset and cultural belief, cost of implementing GSCM, lack of top management support, uncertainty, technology (lack of resources) and lack of knowledge and experience. The level of significance of the
Cronbach's Alpha

Coefficient

0.781

0.823

0.912

0.753

0.538

0.825

0.735

Table 3: Barriers to GSCM

\begin{tabular}{ll}
\hline Barriers to GSCM implementation \\
& Lack of government regulations and support \\
1 & systems \\
2 & Cost of implementing GSCM \\
3 & Mindset and cultural belief \\
4 & Lack of top management support \\
5 & Uncertainty \\
6 & Lack of knowledge and experience \\
7 & Technology (lack of resources) \\
\hline
\end{tabular}

barriers to GSCM in each case was evaluated based on Kazaz et al. (2008) and Amade et al. (2015). Table 3 below shows the barriers. Five of the barriers to GSCM implementation were found to be very significant $(3.4<<4.2)$ and the other two were found to be extremely insignificant $(<3.4)$. Lack of knowledge and experience ranked first with mean item score (MIS) of 3.85, while uncertainty ranked least with an index of 2.38 .

\subsection{Discussion of results}

These findings are consistent with studies mentioned in the literature review. The main barrier to GSCM implementation is the lack of knowledge and experience, this findings is consistent with that of Ojo et al. (2014) who were of the view that knowledge is power and informative as well. A prior knowledge of information before hand would help in salvaging a bad situation way before it gets out of hand. The lack of knowledge to GSCM implementation in most developed climes and Nigeria in particular exposes us to need to get acquainted with the use of this laudable initiative called GSCM via education and other capacity building media. Similar barrier to GSCM was also found by Davies and Davies (2017), Ojo et al. (2014), Enshassi and Mayer (2005), Dashore and Sohani (2013). 
This issue can be taken care of by creating awareness on the need to adopt GSCM by reeling out the benefits associated with its implementation.

The second important barrier to GSCM implementation is lack of top management support and commitment in the implementation of GSCM. Balasubramanian (2012) and Niemann et al. (2016) also found out that lack of top management's support is a great deal of hindrance to GSCM implementation. Top managers of an organization must clearly understand the nexus between profit maximization, performance and GSCM with a view to enhancing their drive to GSCM implementation. In order to be ahead of your peers in the industry, it is incumbent for all and sundry to join hands in moving the organization forward irrespective of one's position or job within the organization.

In addition, the respondents adjudged that the cost of implementing GSCM is another key barrier to GSCM implementation. This finding is corroborated by other studies of (Niemann et al., 2016; Srivastava 2007; Walker et al., 2008). The cost of deploying GSCM and its ancillaries viz; sourcing of materials and selection, product design, production processes, and the final delivery of the end product to end-users. Others are lack of government regulations and support systems, mindset and cultural belief, technology (lack of resources) and uncertainty.

\section{CONCLUSIONS}

This study adopted a questionnaire survey approach in investigating the barriers to GSCM implementation on construction projects in Nigeria. Practitioners within the construction industry in Imo State were surveyed. The results showed that the most critical barriers to GSCM implementation includes "lack of knowledge and experience, "lack of top management's support", "cost of implementing GSCM", "lack of government regulations and support system" "mindset and cultural relief", "technology (lack of resources)" and "uncertainty". Due to the nature of the Nigerian construction industry, as well as other environmental issues occurring in Imo State that are mainly related to the market conditions, one of the mean key issues of resolving the major barriers to GSCM in the implementation of construction projects is mainly attributed to government's support. Hence, it is imperative to build a collaborative alliance between government and the industry professionals with a view to streamlining the activities of the industry. The public authorities can lead this GSCM initiative by way of a policy direction which will serve as a guide to the industry players. Finally, the industry players will be willing to adopt GSCM and help to build a healthy sustainable construction market in Nigeria.

Certain limitation are associated with this work, notable amongst them is that the questionnaire survey was conducted in Imo State, a relatively developed region in the south eastern area of Nigeria. Hence, the outcomes of this study can appropriately be used to compare with other cities in Nigeria, but may vary with that of other advanced climes of the world. Future research opportunities can be conducted on similar studies in other parts of Nigeria to validate these findings. It is also imperative to note that people's behaviour to a greater extent may affect their decisions to adopt or implement GSCM. Therefore, studies needs to be carried out to investigate the attitudes and knowledge of construction professionals as regards GSCM in comparison with policy makers.

\section{REFERENCE}

Abah, E., \& Adamu, A. D. (2017). Evaluation of Nigerian construction industry preparedness to adopt supply chain management, PM World Journal, 6, pp. $1-21$.

Abbasi, M., \& Nilsson, F. (2012). Themes and challenges in making supply chains environmentally sustainable. Supply Chain Management, 17(5), pp. 517-530. DOI : $10.1108 / 13598541211258582$.

Ahiakwo, O. A. (2014). Improving construction processes in Nigeria using last planner system (United Kingdom: University of Wolverhampton)

Ahmed, S. S., Akter, T., \& Ma, Y. (2018). Green supply chain management 
(GSCM) performance implemented by the textile industry of Gazipur district, Dhaka. Logistics, 2(21)

Alhamali, R. M. (2019). Critical success factors for green supply chain management practices: an empirical study on data collected from food processing companies in Saudi. Arabia. African Journal of Business Management, 13(5), pp. 160-167.

Amade, B., Ubani, E. C., Amaeshi, U. F., \& Okorocha, K. A. (2015). Factors for containing failure and abandonment of public sector construction projects in Nigeria, Journal of Building Performance, 6(1), pp. 63-76.

Balasubramanian, S. (2012). Hierarchical framework of barriers to green supply chain management in the construction sector Journal of Sustainable Development, 5(10), pp. 15-27.

Benny, M., \& Joy, A. (2018). Green supply chain management in construction industry: A review International Research Journal of Engineering Technology, 5(11), pp. 661-665.

Dashore, K., \& Sohani, N. (2013). Green supply chain management-barriers \& drivers: A review. International Journal of Engineering Research \& Technology, 2(4), pp. 2021-2030.

Dassah, E. T., \& Nimlyat, P. S. (2010). The role and responsibilities of professionals in the built environment in contributing to sustainable development in Nigeria. Journal of Science and Multidisciplinary Research, 2,40-47.

Davies, O. O., \& Davies, I. O. E. (2017). Barriers to implementation of sustainable construction techniques. MAYFEB Journal of Environmental Science, 2, pp. 1-9.

Elbarkouky, M. M. G., \& Abdelazeem, G. (2013). A green supply chain assessment for construction projects in developing countries. WIT Transactions in Ecology and Environment, The Sustainable City, 2, pp. 1331-1341.

Enshassi, A., \& Mayer, P. E. (2005). Barriers to the application of sustainable construction concepts in Palestine Proc.
World. Sustainable Conf. (Tokyo), pp. 4624-4628.

Govindan, K., Mathiyazhagan, K., Kannan, D., \& NoorulHaq, A. (2014). Barriers analysis for green supply chain management implementation in India industries using analytic hierarchy process. Journal of Production Economics, 147, pp. 555-568.

Khan, S. A. R. (2018). Introduction of green supply chain management. (Beijing: School of Economics and Management, Tsinghua, Beijing, China), pp. 1-7.

Kulkarni, P. B., Ravi, K., \& Patil, S. B. (2017). An investigation on green supply chain management and its scope in Indian construction industries. International Journal of Research and Scientific Innovation, 4(9), pp. 50-53.

Kumar, R., \& Shekhar, S. (2013). Green supply chain management-a review. International Journal of Research in Aeronautical and Mechanical Engineering, 1(7), pp. 245-255.

Luthra, S., Kumar, V., Kumar, S., \& Haleen, A. (2011). Barriers to implement green supply chain management in automobile industry using interpretive structural modelling technique: an Indian perspective. Journal of Industrial Engineering and Management, 4 (2), pp. 231-257.

Mathiyazhagan, K., Govindan, K., NoorulHaq, A., \& Geng, Y. (2013). An ISM approach for the barrier analysis in implementing green supply chain management. Journal of Cleaner Production, 47, pp. 283-297.

Niemann, W., Kotze, T., \& Adamo, F. (2016). Drivers and barrier of green supply chain management implementation in the Mozambican manufacturing industry. Journal of Contemporary Management, 13, pp. 977-1013.

Ojo, E., Mbowa, C., \& Akinlabi, E. T. (2014). Barriers in implementing green supply chain management in construction industry. Proceedings of the 2014 International Conference on Industrial Engineering and Operations Management Bali, Indonesia, pp. 19741981. 
Pallant, J. (2005). SPSS Survival Manual: A Step by Step Guide to Data Analysis using SPSS (Sydney: Allen \& Unwin).

Peprah, J. A., Opoku-Fofie, I., \& Nduro, K. (2016). Factors influencing green supply chain in the mining sector in Ghana. European Journal of Logistics, Purchasing and Supply Chain Management, 4 (1), pp. 32-50.

Persson, U., Landin, A., Olander, S., \& Persson, M. (2008). Sustainable construction management at a project level: A modified environmental management system structure, Conference "World Sustainable Building Conference", Melbourne, Australia, Conference Proceedings, pp. 1-7.

Saunders, M., Lewis, P., \& Thornhill, A. (2007). Research Methods for Business Students 4, ed (London: Sage Publications Inc).

Somekh, M., \& Lewin, C. (2004). Research Methods in the Social Sciences. (London: Sage Publications Inc).

Srivastava, S. K. (2007). Green supply chain management: a state of the art literature review. International Journal of Management Reviews, 9(1), pp. 53-80.
Walker, H., Sisto, L. D., \& Mcbain, D. (2008). Drivers and barriers to environmental supply chain management practices: lessons from public and private sectors. International Journal of Purchasing and Supply Management, 14, pp. 69-85.

Wibowo, M. A., Handayani, N. U., \& Mustikasari, A. (2018). Factors for implementing green supply chain management in the construction industry. Journal of Industrial Engineering and Management, 11(4), pp. 651-679.

Wyawahare, A., \& Udawatta, N. (2017). A framework for successful implementation of green supply chain management in construction organizations (Epic Series in Education), pp. 402-410.

Zulkefli, N. S., Mahmud, F., \& Zainudin, N. M. (2019). A survey on green supply chain management challenges in the Malaysian construction industry, In FGIC $2^{\text {nd }}$ Conference on Governance and Intergrity, pp. 1202-1214.

Zuofa, T., \& Ochieng, E. (2017). Sustainability in construction project delivery: A study of experienced project managers in Nigeria. Project Management Journal, 47(6), pp. 44-55. 